\title{
Topical Ampicillin in the Appendicectomy Wound: Report of Double-blind Trial
}

\author{
J. W. S. RICKETT, $* \dagger$ F.R.C.S. ; B. T. JACKSON, $* \ddagger$ F.R.C.S.
}

British Medical fournal, 1969, 4, 206-207

$S^{n}$ ummary : One hundred and thirty unselected patients undergoing appendicectomy were treated with topical ampicillin powder or topical placebo powder (lactose) before closing the wound. The postoperative wound infection rates were $3 \%$ in the ampicillin-treated group and $24 \%$ in the control group, a significant difference. This difference was not influenced by the degree of inflammation in the appendix. No side-effects of treatment were observed.

\section{Introduction}

Appendicectomy is often complicated by the development of postoperative wound infection. The overall incidence varies widely in different reports, but probably averages about $25 \%$ (Vinnicombe, 1964 ; Moloney et al., 1950), being related to the severity of inflammation in the removed appendix. The incidence when a normal appendix is removed may be as high as $4 \%$ (Barnes et al., 1962), whereas in the case of perforative appendicitis it may rise to $46 \%$ (Gilmour and Lowdon, 1952). Such postoperative sepsis is the most common complication of appendicectomy, and an effective means of prevention has long been sought.

Nash and Hugh (1967) reported a greatly reduced wound infection rate after colonic operations by the application of topical ampicillin powder to the wound before closure of the abdomen. Ryan (1967) has shown similar results with topical penicillin solution in a large series of herniorrhaphies.

Prompted by these papers, we have investigated the use of topical ampicillin in appendicectomy wounds and report here the results of a double-blind trial in an unselected series of 130 appendicectomies.

\section{Method}

All appendicectomies performed between May and September 1968 at St. Peter's Hospital, Chertsey, Surrey, were studied. These included not only operations for acute appendicitis but also cold appendicectomies, on the grounds that there may be a significant incidence of wound infection in these non-inflamed cases (Barnes et al., 1962). The only criterion for exclusion from the trial was a history of penicillin sensitivity.

Phials were prepared containing either $500 \mathrm{mg}$. of ampicillin powder or an equal volume of a freely soluble sterile white placebo powder (lactose). The phials were numbered randomly and the code was kept in a sealed envelope until completion of the trial. The inpatient hospital management of patients in the trial in no way differed from the usual routine, and the following policy was observed in all cases:

A corrugated plastic drain was inserted into the peritoneal cavity in cases of severe local peritonitis or generalized peritonitis due to perforation. The drain was brought out through a separate stab incision some distance away from the wound, waterproof

* Surgical Registrar, St. Peter's Hospital, Chertsey, Surrey. t Present address: St George's Hospital, London S.W.1. $\ddagger$ Present address: 9 Thomas's Hospital, London S.E.1. dressing of the wound being used to prevent contamination from the drain. In no instance was the wound itself drained in any way.

A phial of powder was emptied into the muscle layers after closing the peritoneum. All layers of the wound were closed by means of catgut. Black silk sutures were used for the skin. Systemic ampicillin was given only in cases of gross peritoneal contamination and peritonitis; no other antibiotics were used, nor were antibiotics given for wound infection.

Sutures were removed on the sixth day in the case of children or on the seventh day in the case of adults. In deciding on the state of the wound postoperatively, the criteria of Ljungqvist (1964) were adopted. The wound was either clean or infected. It was infected if at any time a purulent discharge appeared. If a serous discharge appeared it was swabbed, cultured, and classified according to the result of culture. All patients were seen at follow-up three weeks later. Any wounds which discharged after the patients had returned home were included in the infected group.

\section{Results}

A total of 133 cases were recorded in the study, but three of these had to be excluded for the following reasons. One patient had a history of penicillin sensitivity, one died postoperatively of peritonitis, and in one case no note was made concerning the state of the wound at the time sutures were removed.

Of the 130 cases that were analysed 66 received topical placebo and $16(24 \%)$ of them became infected, while 64 received topical ampicillin and $2(3 \%)$ of them became infected. A similar trend is found if cases of acute appendicitis alone are considered: $11(23 \%)$ out of 47 placebo cases became infected, while only two (4\%) out of 46 ampicillintreated cases became infected. The numbers in the two groups requiring intraperitoneal drainage (severe cases) are given in Table I, which shows that similar proportions of both groups

TABLE I.-Numbers of Patients Requiring Intraperitoneal Drainage and Postoperative Antibiotics in Both Ampicillin and Placebo Groups

\begin{tabular}{|c|c|c|c|c|c|c|}
\hline & & \multirow[t]{2}{*}{$\begin{array}{l}\text { Total } \\
\text { No. }\end{array}$} & \multicolumn{2}{|c|}{$\begin{array}{l}\text { Receiving } \\
\text { Postoperative } \\
\text { Antibiotics }\end{array}$} & \multicolumn{2}{|c|}{$\begin{array}{c}\text { Requiring } \\
\text { Intrapeii.onea } \\
\text { Drairage }\end{array}$} \\
\hline & & & No. & $\%$ & No. & $o_{i}$ \\
\hline $\begin{array}{l}\text { Placebo } \\
\text { Ampicillin } \quad \ldots\end{array}$ & 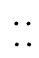 & $\begin{array}{l}66 \\
64\end{array}$ & $\begin{array}{l}15 \\
11\end{array}$ & $\begin{array}{l}23 \\
17\end{array}$ & $\begin{array}{r}9 \\
10\end{array}$ & $\begin{array}{l}14 \\
16\end{array}$ \\
\hline Total & $\ldots$ & 130 & 26 & 20 & 19 & 15 \\
\hline
\end{tabular}

TABLE II.-Infection Rates in All Cases

\begin{tabular}{|c|c|c|c|c|c|}
\hline & \multicolumn{2}{|c|}{ Placebo } & \multicolumn{2}{|c|}{ Ampicillin } & \multirow[b]{2}{*}{$\mathbf{P}$} \\
\hline & $\begin{array}{l}\text { Total } \\
\text { No. }\end{array}$ & $\begin{array}{c}\text { No. } \\
\text { Infected }\end{array}$ & $\begin{array}{l}\text { Total } \\
\text { No. }\end{array}$ & $\begin{array}{c}\text { No. } \\
\text { Infected }\end{array}$ & \\
\hline 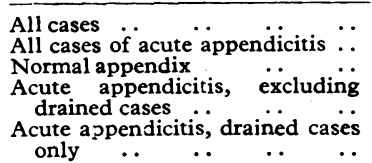 & $\begin{array}{r}66 \\
47 \\
19 \\
39 \\
8\end{array}$ & $\begin{array}{r}16 \\
11 \\
5 \\
8 \\
3\end{array}$ & $\begin{array}{l}64 \\
46 \\
18 \\
36 \\
10\end{array}$ & $\begin{array}{l}2 \\
2 \\
0 \\
1 \\
1\end{array}$ & $\begin{array}{l}\ll 0.01 \\
<0.02 \\
<0.05\end{array}$ \\
\hline
\end{tabular}


came into this category and that similar proportions in both groups received systemic antibiotics. The groups are therefore comparable and infection rates within the groups are not influenced by these two factors. The difference in infection rates according to the severity of inflammation is given in Table II, and Table III relates the infection rate to the type of incision used. The two patients who developed wound infection after having received topical ampicillin had severe appendicitis ; in one perforation occurred.

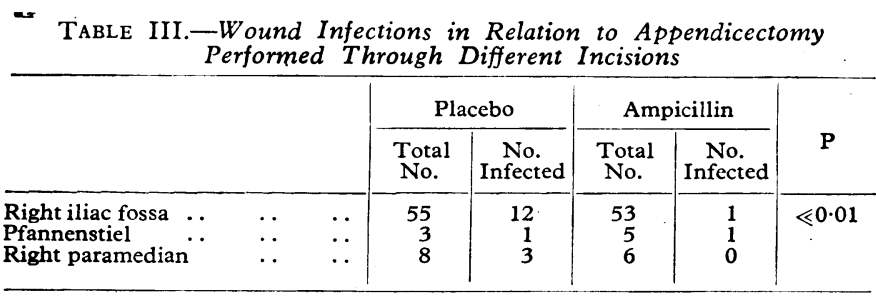

Most patients had a gridiron incision in the right iliac fossa (Table III). Operations in which a Pfannenstiel or right paramedian incision was used showed a similar trend of lowered wound infection in the treated cases, but the numbers were too small for statistical analysis. No sensitivity reactions were recorded, nor were any side-effects noted in any of the patients.

\section{Discussion}

Methods to reduce postoperative wound infection have fallen into three groups. Firstly, systemic antibiotics have been used in several large trials, but, despite the occasional enthusiastic report (Bernard and Cole, 1964), are generally thought to be ineffective (Barnes et al., 1959; Karl et al., 1966; Report of Ad Hoc Committee, 1964). Cole and Bernard (1961) investigated the use of systemic antibiotics specifically in acute appendicitis and found that such treatment had no value in preventing postoperative wound sepsis. Secondly, wound drainage has long been used to prevent subcutaneous pus formation, and this method was investigated in relation to appendicectomy by Vinnicombe (1964). The method was shown to reduce wound infection, but $13(17 \cdot 8 \%)$ out of 73 drained cases became infected. Thirdly, antibacterial substances may be applied to the wound at the time of operation. Most of the recent reports state that an antibiotic spray (neomycin, polymyxin $\mathrm{B}$, and bacitracin) has been used, and the results obtained have been conflicting (Gibson, 1958; Forbes, 1961 ; Fielding et al., 1965 ; Caro et al., 1967). Stoller (1965) investigated the use of such an aerosol in acute appendicitis and found it ineffective.

Wound infection has been significantly reduced in animals by the use of topical antibiotic irrigation (Singleton et al., 1959 ; Singleton and Julian, 1960 ; Hopson et al., 1968), and, using a similar method in man, Ryan (1967) reduced his infection rate in a series of 6,849 herniorrhaphies from $1.54 \%$ to $0 \cdot 15 \%$. Nash and Hugh (1967), using topical ampicillin sprinkled into the wounds of patients undergoing colonic operations, significantly lowered their infection rate from $41 \%$ to $3 \%$. The results reported in the present paper seem to confirm the value of this technique.

No attempt has been made to grade the severity of inflammation of the appendix, but severely inflamed and perforated appendices were treated by intraperitoneal drainage in addition to appendicectomy. Nevertheless, the reduction in postoperative wound infection in ampicillin-treated cases is reflected throughout all groups (Table II).

The use of topical antibiotics seems logical if it is accepted that contamination takes place when delivering an infected organ through the anterior abdominal wall; in the present series cultures of every wound infection grew large-bowel organisms, thus supporting this proposition. Ampicillin is of low toxicity, permitting its use in sufficient quantity to ensure high local concentration. Its broad spectrum is effective against organisms that cause post-appendicectomy infection, and its use is unlikely to cause superinfection elsewhere in the patient. This study indicates that topical application of this drug reduces postoperative wound infection following appendicectomy.

We would like to thank Mr. K. W. Wilkinson, Mr. C. J. Anders, and $\mathrm{Mr}$. A. Eley for help and encouragement in the preparation of this paper. We also wish to thank Dr. E. T. Knudsen, of Beecham Research Laboratories, who supplied specially packaged phials of ampicillin and placebo. Miss W. M. Elliott gave valuable help with statistics.

REFERENCES

Barnes, B. A., Behringer, G. E., Wheelock, F. C., and Wilkins, E. W. (1962). Annals of Surgery, 156, 703.

Barnes, J., Pace, W. G., Trump, D. S., and Ellison, E. H. (1959). Archives of Surgery, 79, 190

Bernard, H. R., and Cole, W. R. (1964). Surgery, 56, 151.

Caro, D., Reynolds, K. W., and Desmith, J. (1967). British fournal of Clinical Practice, 21, 605.

Cole, W. R., and Bernard, H. R. (1961). American Surgeon, 27, 29.

Fielding, G., Rao, A., and Davis, N. C. (1965). Medical fournal of Australia, 2, 159.

Forbes, G. B. (1961). Lancet, 2, 505.

Gibson, R. M. (1958). British Medical fournal, 1, 1326.

Gilmour, I. E. W., and Lowdon, A. G. R. (1952). Edinburgh Medical fournal, 59, 361 .

Hopson, W. B., Britt, L. G., Sherman, R. T., and Ledes, C. P. (1968) fournal of Surgical Research, 8, 261.

Karl, R. C., Mertz, J. J., Veith, F. J., and Dineen, P. (1966). Nerw England Medical fournal, 275, 305.

Ljungqvist, U. (1964). Lancet, 1, 1095.

Moloney, G. E., Russell, W. T., and Wilson, D. C. (1950). British fournal of Surgery, 38, 52 .

Nash, A. G., and Hugh, T. B. (1967). British Medical fournal, 1, 471 Report of Ad Hoc Committee (1964). Annals of Surgery, 160, Suppl. No. 2.

Ryan, E. A. (1967). British fournal of Surgery, 54, 324. Singleton, A. O., Davis, D., and Julian, J. (1959). Surgery, Gynecology
and Obstetrics, 108, 389 .

Singleton, A. O., and Julian, J. (1960). Annals of Surgery, 151, 912.

Stoller, J. L. (1965). British fournal of Clinical Practice, 19, 687.

Vinnicombe, J. (1964). British fournal of Surgery, 51, 328. 